\title{
PREPARAÇÃO E CARACTERIZAÇÃO DE FOTOCATALISADORES DE ÓXIDO DE NIÓBIO APLICADOS NA PRODUÇÃO DE HIDROGÊNIO UTILIZANDO GLICEROL COMO AGENTE DE SACRIFÍCIO*
}

\author{
Bianca Proença ${ }^{1}$ \\ Caroline Antunes Correa ${ }^{2}$ \\ Melissa Machado Rodrigues ${ }^{3}$ \\ Maurício Oliveira Vaz ${ }^{4}$ \\ Juan Bussi ${ }^{5}$ \\ Sérgio Ribeiro Teixeira \\ Célia de Fraga Malfatti ${ }^{7}$ \\ Iduvirges Lourdes Müller ${ }^{8}$
}

\section{Resumo}

Fotocatalisadores de nióbio foram obtidos por anodização a $15 \mathrm{~V}$, utilizando uma solução de $\mathrm{K}_{2} \mathrm{HPO}_{4} 10 \%$ p/p em glicerol anidro como eletrólito por 15 minutos. As amostras foram caracterizadas por difração de raios- $X$ para avaliação da estrutura cristalina obtida. A fotodegradação do glicerol (utilizado como agente de sacrifício) foi avaliada pela técnica de cromatografia líquida de alta eficiência.

Palavras-chave: Nióbio; Hidrogênio; Fotocatálise; Anodização.

\section{PREPARATION AND CHARACTERIZATION OF NIOBIUM OXIDE APPLIED IN PHOTOGENERATION H2 USING GLYCERL AS SACRIFICE AGENT \\ Abstract}

Photocatalysts of niobium were obtained by anodization process at $15 \mathrm{~V}$ by using a solution of $\mathrm{K} 2 \mathrm{HPO} 410 \% \mathrm{w} / \mathrm{w}$ anhydrous glycerol as the electrolyte for 15 minutes. The samples were characterized by X-ray diffraction to evaluate the crystal structure obtained. The photodegradation of glycerol (used as a sacrificial agent) was assessed by liquid chromatography of high efficiency.

Keywords: Niobium; Hydrogen; Photocatalysis; Anodizing.

1 Bacharel em Química Industrial, Química, Mestranda em Engenharia, Depto. de Metalurgia, UFRGS, Porto Alegre, Rio Grande do Sul, Brasil.

2 Eng. Metalúrgica, Graduanda, Estudante, Depto. de Metalurgia, UFRGS, Porto Alegre, RS, Brasil.

3 Bacharel em Química Industrial, Doutora, Pós-doutoranda em Engenharia, Depto. de Metalurgia, UFRGS, Porto Alegre, RS, Brasil.

4 Bacharel em Física, Físico, Mestrando em Ciência dos Materiais, Instituto de Física, UFRGS, Porto Alegre, RS, Brasil.

5 Doutor, Professor, Laboratorio de Fisicoquímica de Superficies, DETEMA, Facultad de Química, Universidad de la República, Montevideo, Uruguai.

6 Doutor, Professor, Instituto de Física, UFRGS, Porto Alegre, Rio Grande do Sul, Brasil.

7 Eng. Metalúrgica, Doutora, Professor, Depto. de Metalurgia, UFRGS, Porto Alegre, RS, Brasil.

8 Eng. Eletricista, Pós-doutora, Professor, Depto. de Metalurgia, UFRGS, Porto Alegre, RS, Brasil. 


\section{INTRODUÇÃO}

Desde o início do século 20, o planeta sofre com a exploração de seus recursos naturais, com a poluição do ar e a degradação da terra [1]. A estratégia que atualmente tem sido explorada é a utilização de uma energia que não tenha como base carbono em seus subprodutos.

Uma descoberta há cerca de 40 anos (1972) de Fujishima e Honda [2], mostrou que é possível dissociar a água em oxigênio $\left(\mathrm{O}_{2}\right)$ e hidrogênio $\left(\mathrm{H}_{2}\right)$ na presença de luz, utilizando como fotocatalisador um óxido de metal semicondutor. O hidrogênio gerado neste processo pode ser convertido em eletricidade em uma célula a combustível, não havendo qualquer geração de resíduos à base de carbono.

Muitos pesquisadores têm sugerido a produção de uma variedade de óxidos de metais semicondutores para a utilização como fotocatalisadores, tais como, por exemplo, $\mathrm{TiO}_{2}, \mathrm{Ta}_{2} \mathrm{O}_{5}, \mathrm{VO}_{2}$ e $\mathrm{Nb}_{2} \mathrm{O}_{5}$ para o fotoprodução de $\mathrm{H}_{2}$ [3].

Nióbio surge como uma excelente alternativa como fotocatalisador, pois ele tem uma banda de energia adequada $(3,4 \mathrm{eV})$ para fotólise da água. O Brasil possui as reservas de nióbio mais abundantes do mundo [4], e isso se torna mais um atrativo para o estudo desse material, além disso, há vários relatos de obtenção de óxidos de nióbio por anodização [5-6].

Para aumentar a eficiência da atividade fotocatalítica, e melhorar a produção de hidrogênio, são utilizados reagentes de sacrifício, por exemplo, metanol, etanol e etilamina [7]. Neste trabalho, lâminas de $\mathrm{Nb}_{2} \mathrm{O}_{5}$ foram sintetizadas sobre uma placa de nióbio por uma técnica de anodização controlada, e a sua aplicação em fotogeração de hidrogênio pela reação de quebra da água utilizando glicerol como um agente de sacrifício, foi avaliada.

\section{MATERIAIS E MÉTODOS}

As amostras de $\mathrm{Nb}$ (fornecidas pela $\mathrm{CBMM}$ ) foram lixadas e quimicamente atacadas com uma solução $5 \mathrm{M} \mathrm{HF}$ e $11 \mathrm{M} \mathrm{HNO}_{3}$ durante 5 minutos. Após o pré-tratamento, as amostras foram anodizadas à $15 \mathrm{~V}$ por 15 min usando como eletrólito uma solução de $\mathrm{K}_{2} \mathrm{HPO}_{4}$ a $10 \% \mathrm{p} / \mathrm{p}$ em glicerol anidro a $180^{\circ} \mathrm{C}$. Após o processo de anodização realizou-se um tratamento térmico em atmosfera de $\mathrm{Ar}$ à $450^{\circ} \mathrm{C}$ durante $30 \mathrm{~min}$ (com rampa de aquecimento de $2{ }^{\circ} \mathrm{C} / \mathrm{min}$ ).

As amostras de $\mathrm{Nb}_{2} \mathrm{O}_{5}$ foram caracterizadas por difração de raios-X (DRX) para avaliação da estrutura cristalina.

A atividade fotocatalítica das placas nióbio anodizadas foram avaliadas mediante a fotodegradação de glicerol. Para isso, uma célula tubular de quartzo $(10 \mathrm{~mm}$ de diâmetro e $120 \mathrm{~mm}$ de comprimento) cercada por três lâmpadas tubulares de UV (4 watts cada) contendo duas placas de nióbio anodizadas $\left(8,1 \mathrm{~cm}^{2}\right)$. Os ensaios começaram com um volume de $35 \mathrm{~mL}$ de uma solução aquosa de glicerol $1 \mathrm{mmol} . \mathrm{L}^{-1}$, que é recirculada continuamente através da célula através de uma bomba peristáltica (10 mL min-1). A reação, na presença de luz, ocorreu durante 23 $\mathrm{h}$, adicionando-se oxigênio para promover a oxidação. As alíquotas para amostragem foram retiradas a cada $2 \mathrm{~h}$ de ensaio, e a concentração da solução de glicerol foi analisada por cromatografia líquida de alta eficiência (HPLC) utilizando um equipamento Shimadzu, com detector de índice de refração e uma coluna Rezex тм RHM-monossacarídeos $\mathrm{H}+(8 \%), 300 \times 7,8 \mathrm{~mm}$, e água como fase móvel.

Para obter a comparação frente a outro tipo de fotocatalisador, foi utilizado uma amostra de $\mathrm{TiO} 2$ suportado sobre vidro. Para isso, placas de vidro, previamente 
atacadas com $\mathrm{HF} 10 \% \mathrm{p} / \mathrm{p}$, foram colocados em suspensão de $\mathrm{TiO}_{2}$ em água destilada. Após, as amostras foram aquecidas em forno a $105{ }^{\circ} \mathrm{C}$ para remoção da água. $\mathrm{O}$ processo de imersão foi repetido 4 vezes para obtenção de uma camada lisa. Finalmente, as folhas foram colocadas num forno a $450{ }^{\circ} \mathrm{C}$ durante 2 horas, usando uma taxa de aquecimento de $10{ }^{\circ} \mathrm{C} /$ minuto. As amostras obtidas por esse processo, também passaram por testes de degradação do glicerol.

\section{RESULTADOS E DISCUSSÃO}

O difratograma obtido após o processo de anodização e tratamento térmico é apresentado (Figura 1). O filme de $\mathrm{Nb}_{2} \mathrm{O}_{5}$ obtido apresentou estrutura ortorrômbica, com os picos em $22,7,28,5,36,9,42,6,46,2,48,0,55,5,58,7$ e $63,7^{\circ} 2$ Theta [8, 9].

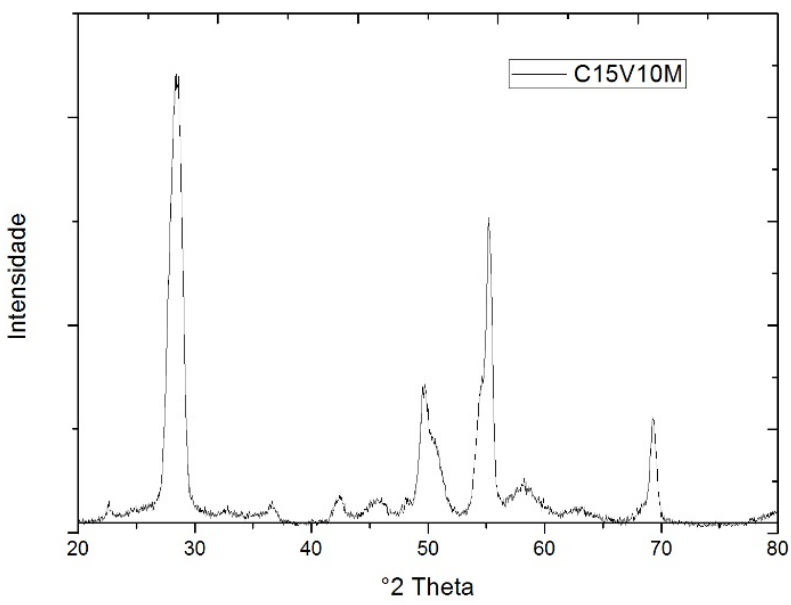

Figura 1. Difratograma de Raios-X da amostra de nióbio anodizada após o tratamento térmico.

O resultado da degradação do glicerol, que foi utilizado como agente de sacrifício na reação de produção de hidrogênio, obtido por cromatografia líquida de alta eficiência é apresentado no gráfico (Figura 2). Para a amostra de $\mathrm{Nb}_{2} \mathrm{O}_{5}$ a eficiência de degradação do glicerol, em $23 \mathrm{~h}$ de reação, foi de 17,8 \%. Já para a amostra de $\mathrm{TiO}_{2} /$ vidro a eficiência de degradação é de $100 \%$. Esses resultados preliminares mostram que a atividade fotocatalítica do $\mathrm{TiO}_{2}$ é muito superior ao óxido de nióbio. Entretanto, melhorias no processo de anodização e uso de corantes podem aumentar a eficiência fotocatalítica do $\mathrm{Nb}_{2} \mathrm{O}_{5}$.

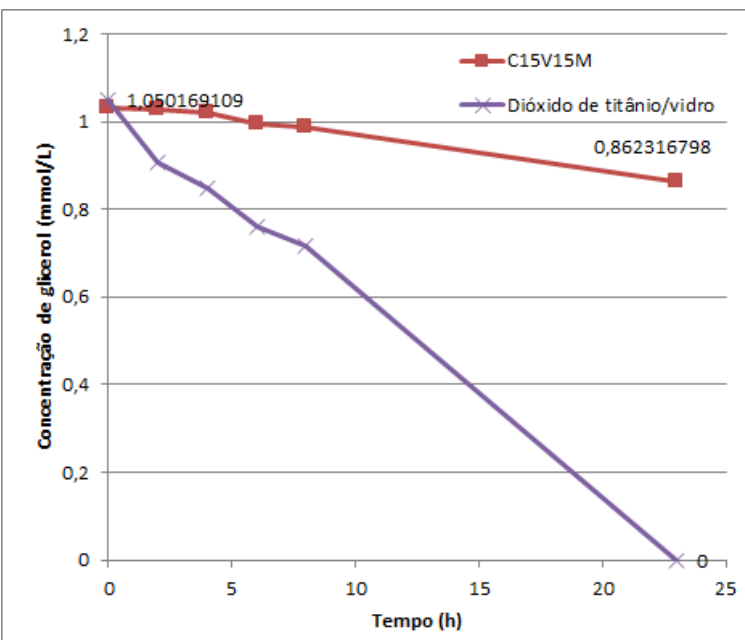

Figura 2. Avaliação da degradação da glicerol em reator fotocatalítico por cromatografia líquida de alta eficiência. 


\section{CONCLUSÃO}

Com os resultados obtidos observa-se que as amostras de pentóxido de nióbio, anodizadas, apresentam atividade fotocatalítica para a produção de hidrogênio. Entretanto, os valores obtidos até o presente momento, ainda estão abaixo dos valores obtidos quando de utiliza $\mathrm{O} \mathrm{TiO}_{2}$. Entretanto, pela grande quantidade de Nióbio disponível nas reservas brasileiras, e pelo Brasil ser o principal produtor do metal, esse fotocatalisador se torna extremamente interessante para a pesquisa no ramo energético, sendo que melhorias podem ser feitas otimizando o processo de obtenção e inserindo substâncias corantes.

\section{Agradecimentos}

Este trabalho foi financiado pelo projeto CAPES/UDELAR. Agradecemos também a CBMM pelas folhas de Nióbio cedidas para a pesquisa.

\section{REFERÊNCIAS}

$1 \quad$ Li K, Martin D, Tang J. Conversion of Solar Energy to Fuels by Inorganic Heterogeneous Systems. Chinese Journal of Catalysis. 2011;32(6-8):879-90.

2 Fujishima A, Honda K. Electrochemical Photolysis of Water at a Semiconductor Electrode. Nature. 1972 Jul 7;238(5358):37-8.

3 Turpeinen E, Raudaskoski R, Pongrácz E, Keiski RL. Thermodynamic analysis of conversion of alternative hydrocarbon-based feedstocks to hydrogen. International Journal of Hydrogen Energy. 2008 Nov;33(22):6635-43.

4 Tarselli MA. Subtle niobium. Nat Chem. 2015 Feb;7(2):180-180.

5 Chen X, Yu T, Fan X, Zhang H, Li Z, Ye J, et al. Enhanced activity of mesoporous $\mathrm{Nb}_{2} \mathrm{O}_{5}$ for photocatalytic hydrogen production. Applied Surface Science. 2007 Aug;253(20):8500-6.

6 Lee K, Yang Y, Yang M, Schmuki P. Formation of Highly Ordered Nanochannel Nb Oxide by Self-Organizing Anodization. Chemistry - A European Journal. 2012 Jul 27;18(31):9521-4.

7 Kudo A, Miseki Y. Heterogeneous photocatalyst materials for water splitting. Chem Soc Rev. 2009;38(1):253-78.

8 Rani RA, Zoolfakar AS, Ou JZ, Field MR, Austin M, Kalantar-zadeh K. Nanoporous $\mathrm{Nb} 2 \mathrm{O} 5$ hydrogen gas sensor. Sensors and Actuators B: Chemical. 2013 Jan;176:149_ 56.

9 Rani RA, Zoolfakar AS, Subbiah J, Ou JZ, Kalantar-zadeh K. Highly ordered anodized $\mathrm{Nb} 2 \mathrm{O} 5$ nanochannels for dye-sensitized solar cells. Electrochemistry Communications. 2014 Mar;40:20-3. 